\title{
Subcutaneous Adipose Tissue from Obese and Lean Adults Does Not Release Hepcidin In Vivo
}

\author{
Lisa Tussing-Humphreys, ${ }^{1}$ Keith N. Frayn, ${ }^{2}$ Steven R. Smith, ${ }^{3}$ Mark Westerman, ${ }^{4}$ \\ A. Louise Dennis, ${ }^{5}$ Elizabeta Nemeth, ${ }^{6}$ Jessica Thomson, ${ }^{1}$ and Cenk Pusatcioglu ${ }^{7}$ \\ ${ }^{1}$ USDA Agricultural Research Service, Louisiana State University AgCenter, \\ Knapp Hall, Baton Rouge, LA 70803, USA \\ ${ }^{2}$ Oxford Center for Diabetes, Endocrinology and Metabolism, University of Oxford, \\ Churchill Hospital, Oxford OX3 7LJ, UK \\ ${ }^{3}$ The Translational Research Institute for Metabolism and Diabetes 2566 Lee Rd, \\ Winter Park, FL 32789, USA \\ ${ }^{4}$ Intrinsic LifeSciences LLC, La Jolla, CA 92037, USA \\ ${ }^{5}$ University of Oxford and NIHR Oxford Biomedical Research Centre, \\ Oxford OX3 7LJ, UK \\ ${ }^{6}$ Division of Pulmonary and Critical Care Medicine, David Geffen School of \\ Medicine, University of California at Los Angeles, 10833 Le Conte Avenue, \\ Los Angeles, CA 90095, USA \\ ${ }^{7}$ Department of Kinesiology and Nutrition, University of Illinois at Chicago, 1919 W. \\ Taylor Street, Room 650, Chicago, IL 60612, USA
}

Received 14 July 2011; Accepted 23 September 2011

Academic Editor: Giamila Fantuzzi

Hepcidin is the main regulator of systemic iron homeostasis and is primarily produced by the liver but is also expressed, at the mRNA-level, in periphery tissues including the subcutaneous and visceral adipose tissue. Obesity is associated with elevated hepcidin concentrations and iron depletion suggesting that the exaggerated fat mass in obesity could contribute significantly to circulating hepcidin levels consequently altering iron homeostasis. The objective of this study was to determine if abdominal subcutaneous adipose tissue (AbScAT) releases hepcidin in vivo and if release is modified by obesity. Arterio-venous differences in concentrations of hepcidin were measured across AbScAT in 9 obese and 9 lean adults. Overall $(n=18)$, mean plasma hepcidin concentrations were significantly higher in arterialized compared to AbScAT venous samples [mean difference (arterialized-AbScAT venous plasma hepcidin) $=4.9 \pm 9.6 \mathrm{ng} / \mathrm{mL}, P=0.04$ ]. Net regional release was not calculated because mean venous plasma hepcidin concentrations were lower than mean arterialized concentrations indicating no net release. Significant correlations between AbScAT venous and arterialized plasma hepcidin concentrations with anthropometric variables were not observed. Findings from this vein drainage study suggest there is no net release of hepcidin from the AbScAT depot and thereby no ability to signal systemically, even in obesity.

KEYWORDS: hepcidin, obesity, adipose tissue, in vivo secretion, iron homeostasis 


\section{INTRODUCTION}

Hepcidin is a small peptide hormone that functions as the homeostatic regulator of systemic iron regulation and as the link between host defense and iron metabolism [1]. Hepcidin directs the flux of iron into plasma by regulating the ferroportin-1 (Fpn) exporter. Ferroportin-1 facilitates the export of iron from intestinal enterocytes, hepatocytes, reticuloendothelial macrophages, and the placenta [2]. When hepcidin binds to Fpn, the two proteins are internalized and degraded within lysosomes [3]. Sensing of circulating iron and iron stores is thought to occur in the liver which is the primary site of hepcidin production $[2,3]$. Hepcidin produced by the liver is simultaneously regulated by iron stores, anemia, hypoxia, and inflammation. When body iron levels are elevated or inflammation or infection is present, liver hepcidin production is increased, resulting in diminished Fpn expression and decreased iron bioavailability (i.e., cellular iron sequestration and decreased dietary iron absorption) [2-4]. Conversely, when body iron levels are depleted or anemia or hypoxia exists, liver hepcidin expression is minimal, allowing for increased dietary iron absorption and mobilization from body stores via active Fpn transporters. However, at any given time, hepcidin expression can be determined by the interplay of these pathways and the relative strength of each of the individual signals [2-7]. The bioactive form of hepcidin, hepcidin-25, is measurable in human plasma, serum, and urine $[8,9]$.

Hepcidin is also expressed in other tissues including the heart, placenta, kidneys, and adipose tissue [4]. Expression within these tissues is believed to be regulated by hypoxia and inflammation and not body iron stores [4]. The impact of acute inflammation on hepcidin mRNA expression in these tissues has been studied in both surgical and injury models. In a recent study, subcutaneous adipose hepcidin mRNA expression and cytokines were significantly increased immediately following cardiac surgery compared to subcutaneous adipose explants assessed before surgery [10]. Also, in an animal model, acute myocardial infarction was associated with increased hepcidin mRNA expression in the ischemic myocardium [11]. However, it is not known if hepcidin expressed in these periphery tissues is actively secreted or has the potential to pose systemic impact.

Obesity is associated with a multitude of metabolic abnormalities, including altered iron homeostasis. In both adults and children, obesity is linked to diminished iron stores and impaired iron absorption despite adequate dietary iron intake [12-22]. Several researchers have demonstrated that serum levels of hepcidin are significantly elevated in obese compared to lean women and children [18, 19, 23], suggesting that hepcidin may play a significant role in iron dysregulation observed in obesity. As individuals become obese, their adipose tissue enlarges and undergoes a series of alterations, including increased production of several proinflammatory factors such as TNF- $\alpha$ and IL-6 [24]. Previous research has demonstrated that several of these proteins, referred to as adipokines, including IL-6 and leptin, are actively secreted by the adipose tissue and can act as endocrine signals bringing about systemic metabolic impact [25, 26]. Recently, Bekri et al. [27] reported that subcutaneous and visceral adipose hepcidin mRNA expression was significantly higher in obese compared to lean women, while liver mRNA expression was similar. This discovery led to the hypothesis that the altered systemic iron homeostasis and increased serum levels of hepcidin observed in obese individuals are, in part, a result of inflamed, exaggerated fat mass secreting bioactive hepcidin into circulation. However, to date, there are no data demonstrating in vivo release of hepcidin from human adipose tissue. Therefore, the objective of this study was to determine if abdominal subcutaneous adipose tissue (AbScAT) releases hepcidin in vivo, and if this release is modified by obesity.

\section{METHODS}

\subsection{Subjects}

Nine obese (body mass index $(\mathrm{BMI}) \geq 30.0 \mathrm{~kg} / \mathrm{m}^{2}$ ) and nine lean (BMI: $18.5-24.9 \mathrm{~kg} / \mathrm{m}^{2}$ ) adult volunteers were recruited from the greater Oxford community by advertisement or from the Oxford BioBank [28]. Participants attended the Oxford Center for Diabetes, Endocrinology and Metabolism Clinical Research 
Unit at the National Institute for Health Research, Oxford Biomedical Research Center. The participants were fasted from 10 PM the night prior and asked to refrain from strenuous exercise and alcohol consumption for 24 hours before the study day. None of the subjects took medication known to affect iron or inflammatory status, and all were normoglycemic based on fasting glucose levels. The protocol was approved by the National Health Service/National Research Ethics Service, and all participants gave written, informed consent.

\subsection{Anthropometric Measures}

Subjects were asked to remove shoes, outdoor clothing, and excess items from their pockets before anthropometric measures were obtained. Weight was measured to the nearest $0.01 \mathrm{~kg}$ using an electronic scale. Height was measured to the nearest $0.5 \mathrm{~cm}$ using a wall-mounted stadiometer. Waist circumference was measured at the midpoint between the bottom of the rib cage and the iliac crest using a flexible tape measure.

\subsection{Cannulas and Blood Sampling}

Arterio-venous differences were measured across AbScAT. Under local anesthesia, a superficial epigastric vein draining AbScAT and an arterialized dorsal hand vein (with the hand kept in a warming box at $60^{\circ} \mathrm{C}$ ) were cannulated [29]. The cannulae were kept patent with an intravenous infusion of $0.9 \%$ saline. After a resting period of $\sim 45 \mathrm{~min}$, blood samples were taken simultaneously from the two sites. Blood was drawn into lithium heparin syringes, and plasma was prepared rapidly at $4{ }^{\circ} \mathrm{C}$ and stored at $-80^{\circ} \mathrm{C}$ until analysis. Previous studies have shown that venous blood from epigastric veins represents the efflux from the adipose tissue bed, and arterio-venous differences across AbScAT yield results that are similar to microdialysis studies $[25,30]$.

\subsection{Plasma Hepcidin Assay}

Plasma hepcidin was determined using a competitive enzyme-linked immunosorbent assay at Intrinsic LifeSciences in La Jolla, Calif, USA. Detailed methods and performance of this assay have been published elsewhere [31]. The reference ranges for plasma hepcidin using this assay are $29-254 \mathrm{ng} / \mathrm{mL}$ in healthy men and $17-286 \mathrm{ng} / \mathrm{mL}$ in healthy women.

\subsection{Blood Flow Measurements and Calculations}

Abdominal subcutaneous adipose tissue blood flow was calculated from the washout of ${ }^{133} \mathrm{Xe}$ assuming a partition coefficient of $10 \mathrm{~mL} / \mathrm{g}$. This method is based on the principle that disappearance of ${ }^{133} \mathrm{Xe}$ is proportional to adipose tissue blood flow [32]. Abdominal subcutaneous adipose tissue plasma flow was calculated as the AbScAT blood flow * (1-hematocrit) [33]. Hematocrit was measured by microcapillary method.

If AbScAT venous plasma hepcidin concentrations are found to be higher than levels in arterialized samples (arterio-venous difference), the net regional release of hepcidin from the AbScAT (ng. $100 \mathrm{~g}$ adipose tissue $^{-1} \cdot \min ^{-1}$ ) will be calculated using the Fick principle, which is the product of the arterio-venous plasma hepcidin difference and AbScAT plasma flow (net regional hepcidin release $=([\mathrm{AbScAT}$ venous plasma hepcidin] - [arterialized plasma hepcidin] * AbScAT plasma flow)) [25]. This value will be calculated for all subjects combined (overall), for the obese and lean groups separately, and on an individual basis.

\subsection{Statistical Analysis}

Demographic data are presented as means (with standard deviations) or frequencies. Anthropometric and biochemical data are presented as means (with standard deviations). Comparisons between the 
TABLE 1: Demographic and clinical characteristics of Caucasian obese and lean adults $(n=18)$.

\begin{tabular}{lcc}
\hline & Obese $(n=9)$ & Lean $(n=9)$ \\
\hline Age (years) & $45.8 \pm 5.3$ & $44.2 \pm 7.9$ \\
Gender (male/female) $[\%(\mathrm{n})]$ & $55.6(n=5) / 44.4(n=4)$ & $22.2(n=2) / 77.78(n=7)$ \\
Body mass index $\left(\mathrm{kg} / \mathrm{m}^{2}\right)^{\dagger}$ & $36.8 \pm 3.7$ & $22.6 \pm 1.4$ \\
Waist circumference $(\mathrm{cm})^{\dagger}$ & $115.1 \pm 10.9$ & $77.7 \pm 5.9$ \\
Arterialized plasma hepcidin $(\mathrm{ng} / \mathrm{mL})$ & $68.7 \pm 48.7$ & $62.0 \pm 67.1$ \\
AbScAT venous plasma hepcidin $(\mathrm{ng} / \mathrm{mL})$ & $64.7 \pm 47.4$ & $56.1 \pm 57.3$ \\
Hematocrit $(\%)$ & $41.4 \pm 0.03$ & $39.3 \pm 0.05$ \\
\hline
\end{tabular}

All biochemical analysis was performed on fasted samples.

Data are presented as means \pm standard deviations or as percentages.

Differences between groups were assessed using Student's $t$-test for continuous variables and Fisher's exact test for categorical variables.

${ }^{\dagger}$ Differed significantly between obese and lean participants $(P<0.0001)$.

AbScAT: Abdominal subcutaneous adipose tissue.

arterialized and venous sites were assessed using paired $t$-tests, and differences between groups were assessed using Student's $t$-tests for continuous variables and Fisher's exact test for categorical variables. To determine if linear relationships existed between arterialized and venous plasma hepcidin concentrations and anthropometric variables, Spearman's correlation coefficients were calculated. All $P$ values were two sided, and the type I error rate was set at 0.05. All analyses were performed using SAS software (version 9.2, 2008, SAS Institute Inc., Cary, NC, USA).

\section{RESULTS}

The demographic and clinical characteristics are presented in Table 1. All participants were identified as Caucasian. Mean age did not differ significantly between obese and lean participants (45.8 versus 44.2 years, resp.). Although there were more males in the obese compared to the lean group (obese: $55.6 \%$ $(n=5)$ versus lean: $22.2 \%(n=2)$, resp.), the difference was not statistically significant. As expected, mean BMI and waist circumference were significantly greater $\left(36.8 \mathrm{~kg} / \mathrm{m}^{2}\right.$ versus $22.6 \mathrm{~kg} / \mathrm{m}^{2}$ and $115.1 \mathrm{~cm}$ versus $77.7 \mathrm{~cm}$, resp.) in the obese group. Hematocrit was not statistically different between the obese compared to the lean group; however, when hematocrit was assessed by gender (data not shown), obese men had lower hematocrit compared to lean men (obese: 41.2 versus lean: $46.5 \% ; P=0.48$ ) and obese women had higher hematocrit compared to lean women (obese: 41.8 versus lean: $37.3 \% ; P=0.01$ ). Significant differences between obese and lean groups for AbScAT venous or arterialized plasma hepcidin concentrations were not observed. Also, no differences were observed for AbScAT venous or arterialized plasma hepcidin concentrations when assessed by obese and lean gender groups (data not shown).

Overall (all participants), postabsorptive concentrations of plasma hepcidin were significantly higher in the arterialized compared to the AbScAT venous samples (mean difference (arterialized-venous plasma hepcidin) $=4.9 \pm 9.6 \mathrm{ng} / \mathrm{mL}, P=0.04$ ). When differences in arterialized and venous plasma hepcidin concentrations were assessed by group (obese and lean separately), venous concentrations were lower than arterialized (Figure 1), but these differences failed to reach statistical significance. This may be due to the small sample size within each group. Net regional hepcidin release was not calculated overall or by group because mean venous plasma hepcidin concentrations were lower than mean arterialized plasma concentrations indicating no net hepcidin release. However, in five subjects (Table 2), AbScAT venous concentrations of plasma hepcidin were higher than in the arterialized samples, although the reverse was true for a greater number of participants $(n=12$, adipose tissue blood flow could not be determined for one lean female). Notably, there was no consistent pattern to the hepcidin arterio-venous difference with the obese individuals $(n=3)$ no more likely to show net release than lean participants $(n=2)$ (Fisher's exact test, $P=0.99)$; although women $(n=4)$ were more likely to show net release compared to men $(n=1)$, this 


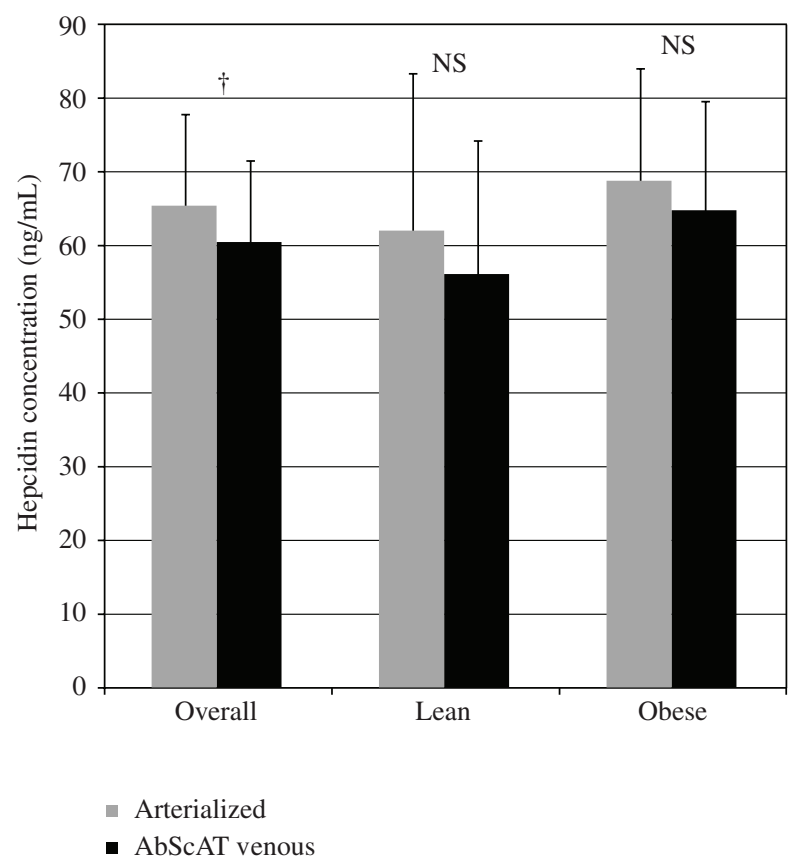

FIGURE 1: Postabsorptive arterialized dorsal hand vein and abdominal subcutaneous adipose tissue (AbScAT) venous plasma concentrations of hepcidin in obese $(n=9)$ and lean $(n=9)$ adults. Comparison between arterialized and venous sites was assessed using paired $t$-tests. ${ }^{\dagger}$ Significantly different at 0.05 level. NS: not significantly different at 0.05 level.

was not statistically significant (Fisher's exact test, $P=0.60$ ). For those demonstrating net hepcdin release from $\mathrm{AbScAT}$, release did not differ between the obese and lean individuals (obese: $9.8 \pm 5.6 \mathrm{ng} \cdot 100 \mathrm{~g}$ adipose tissue ${ }^{-1} \cdot \mathrm{min}^{-1}$ versus lean: $9.9 \pm 7.0 \mathrm{ng} \cdot 100 \mathrm{~g}$ adipose tissue ${ }^{-1} \cdot \mathrm{min}^{-1}$; Student's $t$-test, $P=$ 0.98). Significant correlations between AbScAT venous and arterialized plasma hepcidin concentrations with anthropometric variables were not observed (data not shown).

\section{DISCUSSION}

These data demonstrate, for the first time, that there is no overall net secretion of hepcidin, in vivo, by $\mathrm{AbScAT}$, from fasted obese or lean individuals. Also, no significant correlations were observed between anthropometric measures and arterialized or venous plasma hepcidin concentrations. Collectively, these findings are somewhat surprising as subcutaneous and visceral adipose hepcidin mRNA expression has been reported to be significantly elevated in obese compared to lean women [27], and adipose-derived hepcidin was hypothesized to be associated, in part, with the increased hepcidin concentrations and the iron depletion observed in obesity [27]. Nonetheless, like IL-6 [34], hepcidin has a high turnover rate in plasma [35], and one would anticipate an arterio-venous difference across a tissue if the tissue was consistently and actively releasing significant amounts of the protein [25]. Further, in this study, when assessed overall, venous hepcidin concentrations were significantly lower than arterialized concentrations suggesting that net removal or degradation of hepcidin by AbScAT may be possible. Yet, arterio-venous studies cannot rule out the possibility that subcutaneous adipose-derived hepcidin could still have an autocrine or paracrine effect on tissue-level iron regulation, such as promotion of iron sequestration within the adipose tissue. This effect, however, may be minor considering that a recent study reported that in morbidly obese women, tissue iron content, assessed by Perl's Prussian blue stain, a semiquantitative technique, was minimal in AbScAT [18]. Additional studies including a quantitative approach to assessing adipose tissue iron content would 
TABLE 2: Demographic, body mass index, arterialized plasma and abdominal subcutaneous adipose tissue (AbScAT) venous plasma hepcidin concentrations, and in vivo net regional hepcidin release from AbScAT in obese $(n=9)$ and lean $(n=9)$ subjects.

\begin{tabular}{lccccc}
\hline Gender & Age (years) & $\begin{array}{c}\text { BMI } \\
\left(\mathrm{kg} / \mathrm{m}^{2}\right)\end{array}$ & $\begin{array}{c}\text { Arterialized plasma } \\
\text { hepcidin }(\mathrm{ng} / \mathrm{mL})\end{array}$ & $\begin{array}{c}\text { AbScAT venous plasma } \\
\text { hepcidin }(\mathrm{ng} / \mathrm{mL})\end{array}$ & $\begin{array}{c}\text { Net regional AbScAT } \\
\text { hepcidin release } \\
(\mathrm{ng} \cdot 100 \mathrm{~g} \text { adipose } \\
\left.\text { tissue }^{-1} \cdot \text { min }^{-1}\right)^{*}\end{array}$ \\
\hline Male & 51 & 36.4 & 9.9 & 7.5 & -9.219912 \\
Male & 46 & 41.3 & 59.8 & 67.9 & 16.0832952 \\
Male & 48 & 41.5 & 140 & 133.6 & -19.305216 \\
Male & 44 & 35.9 & 148.7 & 144.4 & -17.088888 \\
Male & 40 & 30.2 & 76.2 & 59.1 & -65.28951 \\
Male & 44 & 22.3 & 9 & 7.4 & -5.53728 \\
Male & 32 & 24.3 & 119 & 99.3 & -18.024318 \\
Female & 56 & 33.8 & 74.1 & 61.6 & -9.828 \\
Female & 39 & 36.1 & 59.1 & 61.4 & 5.231787 \\
Female & 43 & 35.4 & 30.4 & 31.9 & -17.136 \\
Female & 45 & 40.4 & 20.4 & 15.3 & -1.978596 \\
Female & 45 & 21.7 & 21 & 19.3 & NA \\
Female & 57 & 21.3 & 93.9 & 84.9 & 4.871826 \\
Female & 41 & 24.7 & 90.6 & 93.5 & -0.450996 \\
Female & 56 & 23.9 & 6.4 & 6.2 & -1.96371 \\
Female & 43 & 22.8 & 8.5 & 8 & 14.829696 \\
Female & 40 & 21 & 12.9 & 19.2 & -144.338832 \\
Female & 40 & 21.6 & 196.3 & 167 &
\end{tabular}

All biochemical analysis was performed on morning fasting samples.

${ }^{*}$ Net regional hepcidin release $=[($ AbScAT venous plasma hepcidin $]-($ Arterialized plasma hepcidin $)] *$ AbScAT plasma flow. BMI: body mass index; NA: not available due to unreliable adipose tissue blood flow calculation.

be needed to examine the autocrine and paracrine effect of adipose-derived hepcidin in obesity. Also, it is important to note that net secretion of hepcidin was evident in five individuals, but obese were no more likely to show net release compared to lean subjects. Also, no clinical features could clearly distinguish these individuals from those displaying no net secretion although four of the individuals were younger women. Additional larger scale studies are required to better understand this disparity. However, similar results have been reported for tumor necrosis factor- $\alpha(\mathrm{TNF}-\alpha)$, in which the researchers concluded that there was no overall net secretion of TNF- $\alpha$ from AbScAT in a group of obese and lean individuals. Although, like with hepcidin, a few subjects within the group did display net secretion, the authors reported that no clinical or demographic characteristics could explain why TNF- $\alpha$ net secretion was observed in these individuals [25].

Two previous studies $[18,27]$ have demonstrated that hepcidin mRNA expression in AbScAT and visceral adipose tissue from obese women did not differ significantly. However, it is well understood that adipose tissue is not homogenous [36]. Therefore, despite reporting that the AbScAT does not release hepcidin, we cannot exclude the possibility that the visceral adipose depot secretes hepcidin and has an influential role in systemic or localized iron regulation.

Collectively, previous research and findings from this study suggest that liver- and not adipose-derived hepcidin may be associated with the increased systemic hepcidin concentrations and the iron dysregulation observed in obesity. First, hepatic hepcidin mRNA expression was reported to be significantly 
greater than that observed in AbScAT and visceral adipose tissue from obese women $[18,27]$; in one study, it was reported to be more than 700 times greater [18]. Also, Tussing-Humphreys and colleagues [18] reported that liver hepcidin mRNA expression was positively correlated with serum hepcidin concentrations, whereas adipose mRNA expression was not. However, Bekri and colleagues [27] reported that liver hepcidin mRNA expression was similar in hepatic biopsies from obese and lean premenopausal women suggesting that the liver is not the source of increased hepcidin in obesity. But this observation is somewhat flawed as the iron status of the lean women was not described [27] and could have differed considerably from the obese women. As reported by Bekri et al. [27], iron status was depleted, based on transferrin saturation $(<20 \%)$, in $60 \%(n=15)$ of the obese women. Matching the iron status of obese and lean subjects is critical as hepatic hepcidin expression is simultaneously regulated by body iron stores, inflammation, hypoxia, and anemia [2-6]. It is also critical that when matching on iron status, gender and age are also considered, as iron status differs between men and women and also with menopause [37]. Several studies have investigated the regulation of hepatic hepcidin by opposing stimuli and suggest that the strength of the individual stimuli, rather than the hierarchy of signaling pathways, determines hepatic hepcidin production [6, 7]. Thus, restricting a comparison group to healthy, noninflamed, lean men or women (limit to either premenopausal or menopausal) with similar iron status can allow one to evaluate the impact of the inflammatory signal on hepcidin expression in obesity. For example, in a previous study, in which obese and lean premenopausal women were matched on iron status (hemoglobin, transferrin saturation, and ferritin concentrations), median serum hepcidin concentrations (obese: $103.6 \mathrm{ng} / \mathrm{mL}$ versus lean: $16.3 \mathrm{ng} / \mathrm{mL} ; P<0.0001$ ) and hepcidin regulation appeared to differ significantly between the two groups [18]. In the obese women, serum hepcidin was positively correlated with central adiposity and inflammation and weakly correlated with markers of iron status including transferrin saturation, serum transferrin receptor, and serum iron. Conversely, in the lean women, serum hepcidin was strongly correlated with the markers of iron status assessed. This suggests that in obesity, the inflammatory signal counterregulates the signal related to iron depletion which could lead to a modest increase in liver hepcidin production. Interestingly, serum hepcidin concentrations in obese individuals are similar to those reported in healthy, iron-replete individuals [18, 31]. Therefore, if the lean women assessed in the Bekri et al. [27] study were iron replete, it would not be surprising that their liver hepcidin mRNA expression was similar to the obese women and suggests that hepcidin expression in obesity is upregulated, despite underlying iron depletion. Hence, to confirm that liver-derived hepcidin is the source of increased systemic hepcidin concentrations in obesity, obese and lean individuals with similar iron status would need to participate in a hepatic vein catheterization study to assess if hepatic hepcidin release is significantly greater in obesity despite similar iron levels.

This study is not without limitation. First, although the sample size was relatively small and heterogeneous for age and gender, it was not unlike samples reported in other arterio-venous drainage studies investigating adipose tissue physiology [25, 38-40]. Also, the small sample size did not impact our ability to demonstrate that collectively there was no net secretion of hepcidin by AbScAT in vivo from obese and lean individuals as the mean AbScAT venous plasma hepcidin concentrations were significantly lower than arterialized samples, and secretion was not modified by obesity. However, the small sample size likely impeded our ability to observe a similar association when assessed separately within the obese and lean (Figure 1) as the sample size was reduced to only nine individuals per group. Second, this study does not rule out the possibility that AbScAT releases hepcidin at different times of the day or in response to food consumption, exercise, or starvation warranting further investigation. Finally, a comprehensive assessment of iron status and data pertaining to menopause and menstruation for females may have allowed for a more thorough characterization of the findings.

\section{CONCLUSION}

In summary, there was no overall net secretion of hepcidin by AbScAT from obese or lean individuals. The mechanism linking obesity to elevated hepcidin concentrations and iron depletion remains unclear 
although it is attractive to speculate that liver-derived hepcidin stimulated by inflammation and not adiposederived hepcidin plays an important role in this phenomenon. Additional research is required to confirm this hypothesis. Gaining an understanding of the relationship between obesity and diminished iron status, in light of the burgeoning obesity epidemic, is critical since the clinical significance of suffering simultaneously from both morbidities remains unknown [41].

\section{ACKNOWLEDGMENTS}

The collection and shipment of the adipose tissue venous and arterialized samples were funded by the project "Hepatic and adipose tissue and functions in the metabolic syndrome" (HEPADIP, http://www.hepadip.org/), which was supported by the European Commission as an Integrated Project under the 6th Framework Program (Contract no. LSHM-CT-2005-018734). The processing of the adipose tissue venous and arterialized samples by Intrinsic LifeSciences LLC and efforts put forth by Drs. L. Tussing-Humphreys and J. Thomson were supported by the USDA Agricultural Research Service Project no. 6435-51000-00800D. Dr. E. Nemeth's effort was supported by NIH RO1 DK082717.

\section{REFERENCES}

[1] T. Ganz, "Hepcidin and its role in regulating systemic iron metabolism," The American Society of Hematology, pp. 29-507, 2006.

[2] E. Nemeth and T. Ganz, "The role of hepcidin in iron metabolism," Acta Haematologica, vol. 122, no. 2-3, pp. 78-86, 2009.

[3] E. Nemeth and T. Ganz, "Regulation of iron metabolism by hepcidin," Annual Review of Nutrition, vol. 26, pp. 323-342, 2006.

[4] J. F. Collins, M. Wessling-Resnick, and M. D. Knutson, "Hepcidin regulation of iron transport," Journal of Nutrition, vol. 138, no. 11, pp. 2284-2288, 2008.

[5] T. Ganz, "Hepcidin, a key regulator of iron metabolism and mediator of anemia of inflammation," Blood, vol. 102, no. 3, pp. 783-788, 2003.

[6] D. Darshan and G. J. Anderson, "Interacting signals in the control of hepcidin expression," Biometals, vol. 22, no. 1 , pp. 77-87, 2009.

[7] H. Huang, M. Constante, A. Layoun, and M. M. Santos, "Contribution of STAT3 and SMAD4 pathways to the regulation of hepcidin by opposing stimuli," Blood, vol. 113, no. 15, pp. 3593-3599, 2009.

[8] A. Krause, S. Neitz, H. J. Magert et al., "LEAP-1, a novel highly disulfide-bonded human peptide, exhibits antimicrobial activity," FEBS Letters, vol. 480, no. 2-3, pp. 147-150, 2000.

[9] C. H. Park, E. V. Valore, A. J. Waring, and T. Ganz, "Hepcidin, a urinary antimicrobial peptide synthesized in the liver," Journal of Biological Chemistry, vol. 276, no. 11, pp. 7806-7810, 2001.

[10] M. Vokurka, Z. Lacinova, J. Kremen et al., "Hepcidin expression in adipose tissue increases during cardiac surgery," Physiological Research, vol. 59, no. 3, pp. 393-400, 2010.

[11] G. Simonis, K. Mueller, P. Schwarz et al., "The iron-regulatory peptide hepcidin is upregulated in the ischemic and in the remote myocardium after myocardial infarction," Peptides, vol. 31, no. 9, pp. 1786-1790, 2010.

[12] B. J. Wenzel, H. B. Stults, and J. Mayer, "Hypoferraemia in obese adolescents," The Lancet, vol. 2, no. 7251, pp. 327-328, 1962.

[13] C. C. Seltzer and J. Mayer, "Serum iron and iron-binding capacity in adolescents. Ii. Comparison of obese and nonobese subjects," The American Journal of Clinical Nutrition, vol. 13, pp. 354-361, 1963.

[14] K. G. Nead, J. S. Halterman, J. M. Kaczorowski, P. Auinger, and M. Weitzman, "Overweight children and adolescents: a risk group for iron deficiency," Pediatrics, vol. 114, no. 1, pp. 104-108, 2004.

[15] O. Pinhas-Hamiel, R. S. Newfield, I. Koren, A. Agmon, P. Lilos, and M. Phillip, "Greater prevalence of iron deficiency in overweight and obese children and adolescents," International Journal of Obesity, vol. 27, no. 3, pp. 416-418, 2003.

[16] A. Lecube, A. Carrera, E. Losada, C. Hernandez, R. Simo, and J. Mesa, "Iron deficiency in obese postmenopausal women," Obesity, vol. 14, no. 10, pp. 1724-1730, 2006. 
[17] L. M. Tussing-Humphreys, H. Liang, E. Nemeth, S. Freels, and C. A. Braunschweig, "Excess adiposity, inflammation, and iron-deficiency in female adolescents," Journal of the American Dietetic Association, vol. 109, no. 2, pp. 297-302, 2009.

[18] L. M. Tussing-Humphreys, E. Nemeth, G. Fantuzzi et al., "Elevated systemic hepcidin and iron depletion in obese premenopausal females," Obesity, vol. 18, no. 7, pp. 1449-1456, 2010.

[19] I. Aeberli, R. F. Hurrell, and M. B. Zimmermann, "Overweight children have higher circulating hepcidin concentrations and lower iron status but have dietary iron intakes and bioavailability comparable with normal weight children," International Journal of Obesity, vol. 33, no. 10, pp. 1111-1117, 2009.

[20] L. B. Yanoff, C. M. Menzie, B. Denkinger et al., "Inflammation and iron deficiency in the hypoferremia of obesity," International Journal of Obesity, vol. 31, no. 9, pp. 1412-1419, 2007.

[21] C. M. Menzie, L. B. Yanoff, B. I. Denkinger et al., "Obesity-related hypoferremia is not explained by differences in reported intake of heme and nonheme iron or intake of dietary factors that can affect iron absorption," Journal of the American Dietetic Association, vol. 108, no. 1, pp. 145-148, 2008.

[22] M. B. Zimmermann, C. Zeder, S. Muthayya et al., "Adiposity in women and children from transition countries predicts decreased iron absorption, iron deficiency and a reduced response to iron fortification," International Journal of Obesity, vol. 32, no. 7, pp. 1098-1104, 2008.

[23] E. M. del Giudice, N. Santoro, A. Amato et al., "Hepcidin in obese children as a potential mediator of the association between obesity and iron deficiency," Journal of Clinical Endocrinology and Metabolism, vol. 94, no. 12 , pp. 5102-5107, 2009.

[24] A. S. Greenberg and M. S. Obin, "Obesity and the role of adipose tissue in inflammation and metabolism," American Journal of Clinical Nutrition, vol. 83, no. 2, pp. S461-S465, 2006.

[25] V. Mohamed-Ali, S. Goodrick, A. Rawesh et al., "Subcutaneous adipose tissue releases interleukin-6, but not tumor necrosis factor- $\alpha$, in vivo," Journal of Clinical Endocrinology and Metabolism, vol. 82, no. 12, pp. 41964200, 1997.

[26] J. N. Fain, A. K. Madan, M. L. Hiler, P. Cheema, and S. W. Bahouth, "Comparison of the release of adipokines by adipose tissue, adipose tissue matrix, and adipocytes from visceral and subcutaneous abdominal adipose tissues of obese humans," Endocrinology, vol. 145, no. 5, pp. 2273-2282, 2004.

[27] S. Bekri, P. Gual, R. Anty et al., "Increased adipose tissue expression of hepcidin in severe obesity is independent from diabetes and NASH," Gastroenterology, vol. 131, no. 3, pp. 788-796, 2006.

[28] G. D. Tan, M. J. Neville, E. Liverani et al., "The in vivo effects of the Pro12Ala PPAR $\gamma 2$ polymorphism on adipose tissue NEFA metabolism: the first use of the Oxford Biobank," Diabetologia, vol. 49, no. 1, pp. 158-168, 2006.

[29] K. N. Frayn, S. W. Coppack, S. M. Humphreys, and P. L. Whyte, "Metabolic characteristics of human adipose tissue in vivo," Clinical Science, vol. 76, no. 5, pp. 509-516, 1989.

[30] P. Arner and J. Bulow, "Assessment of adipose tissue metabolism in man: comparison of Fick and microdialysis techniques," Clinical Science, vol. 85, no. 3, pp. 247-256, 1993.

[31] T. Ganz, G. Olbina, D. Girelli, E. Nemeth, and M. Westerman, "Immunoassay for human serum hepcidin," Blood, vol. 112, no. 10, pp. 4292-4297, 2008.

[32] P. A. Jansson and P. Lonnroth, "Comparison of two methods to assess the tissue/blood partition coefficient for xenon in subcutaneous adipose tissue in man," Clinical Physiology, vol. 15, no. 1, pp. 47-55, 1995.

[33] S. Klein, J. F. Horowitz, M. Landt, S. J. Goodrick, V. Mohamed-Ali, and S. W. Coppack, "Leptin production during early starvation in lean and obese women," American Journal of Physiology-Endocrinology and Metabolism, vol. 278, no. 2, pp. E280-E284, 2000.

[34] J. V. Castell, T. Geiger, V. Gross et al., "Plasma clearance, organ distribution and target cells of interleukin-6/ hepatocyte-stimulating factor in the rat," European Journal of Biochemistry, vol. 177, no. 2, pp. 357-361, 1988.

[35] J. J. Xiao, W. Krzyzanski, Y. M. Wang et al., "Pharmacokinetics of anti-hepcidin monoclonal antibody Ab 12B9m and hepcidin in cynomolgus monkeys," AAPS Journal, vol. 12, no. 4, pp. 646-657, 2010.

[36] S. R. Smith, J. C. Lovejoy, F. Greenway et al., "Contributions of total body fat, abdominal subcutaneous adipose tissue compartments, and visceral adipose tissue to the metabolic complications of obesity," Metabolism, vol. 50, no. 4, pp. 425-435, 2001.

[37] J. D. Cook, C. A. Finch, and N. J. Smith, "Evaluation of the iron status of a population," Blood, vol. 48, no. 3, pp. 449-455, 1976. 
[38] D. Lyngso, L. Simonsen, and J. Bulow, "Metabolic effects of interleukin-6 in human splanchnic and adipose tissue," Journal of Physiology, vol. 543, no. 1, pp. 379-386, 2002.

[39] J. Saleh, L. K. Summers, K. Cianflone, B. A. Fielding, A. D. Sniderman, and K. N. Frayn, "Coordinated release of acylation stimulating protein (ASP) and triacylglycerol clearance by human adipose tissue in vivo in the postprandial period," Journal of Lipid Research, vol. 39, no. 4, pp. 884-891, 1998.

[40] S. E. McQuaid, K. N. Manolopoulos, A. L. Dennis, J. Cheeseman, F. Karpe, and K. N. Frayn, "Development of an arterio-venous difference method to study the metabolic physiology of the femoral adipose tissue depot," Obesity, vol. 18, no. 5, pp. 1055-1058, 2010.

[41] J. P. McClung and J. P. Karl, "Iron deficiency and obesity: the contribution of inflammation and diminished iron absorption," Nutrition Reviews, vol. 67, no. 2, pp. 100-104, 2009.

\section{This article should be cited as follows:}

Lisa Tussing-Humphreys, Keith N. Frayn, Steven R. Smith, Mark Westerman, A. Louise Dennis, Elizabeta Nemeth, Jessica Thomson, and Cenk Pusatcioglu, "Subcutaneous Adipose Tissue from Obese and Lean Adults Does Not Release Hepcidin In Vivo," TheScientificWorldJOURNAL, vol. 11, pp. 2197-2206, 2011. 


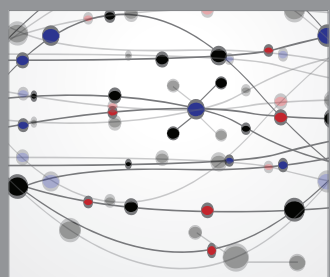

The Scientific World Journal
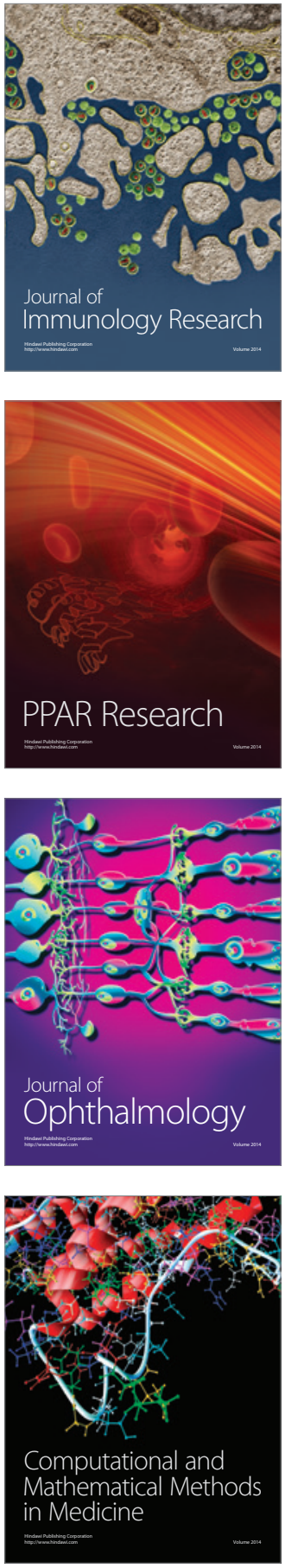

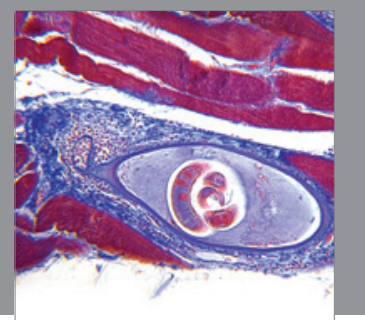

Gastroenterology

Research and Practice
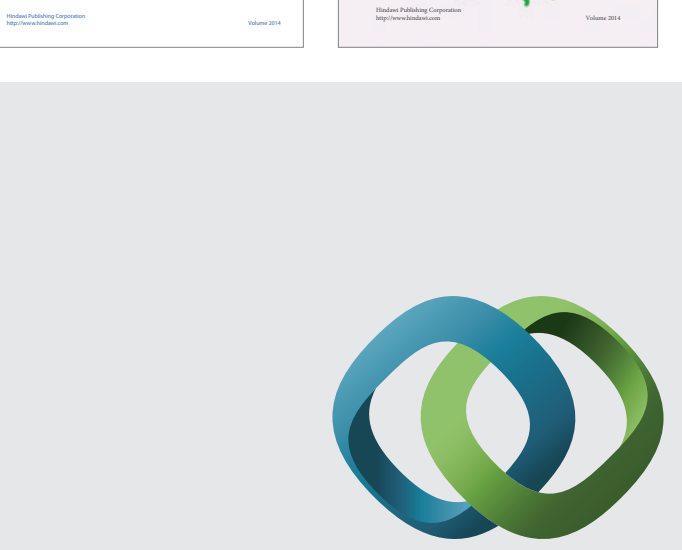

\section{Hindawi}

Submit your manuscripts at

http://www.hindawi.com
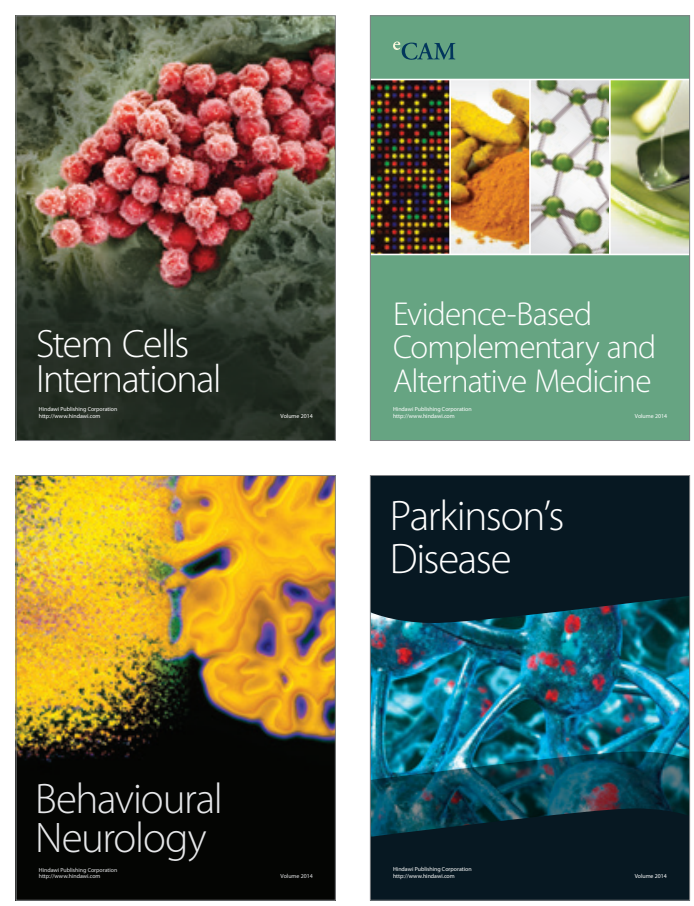

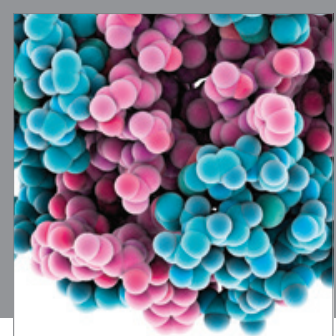

Journal of
Diabetes Research

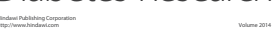

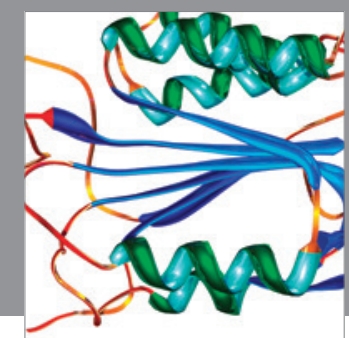

Disease Markers
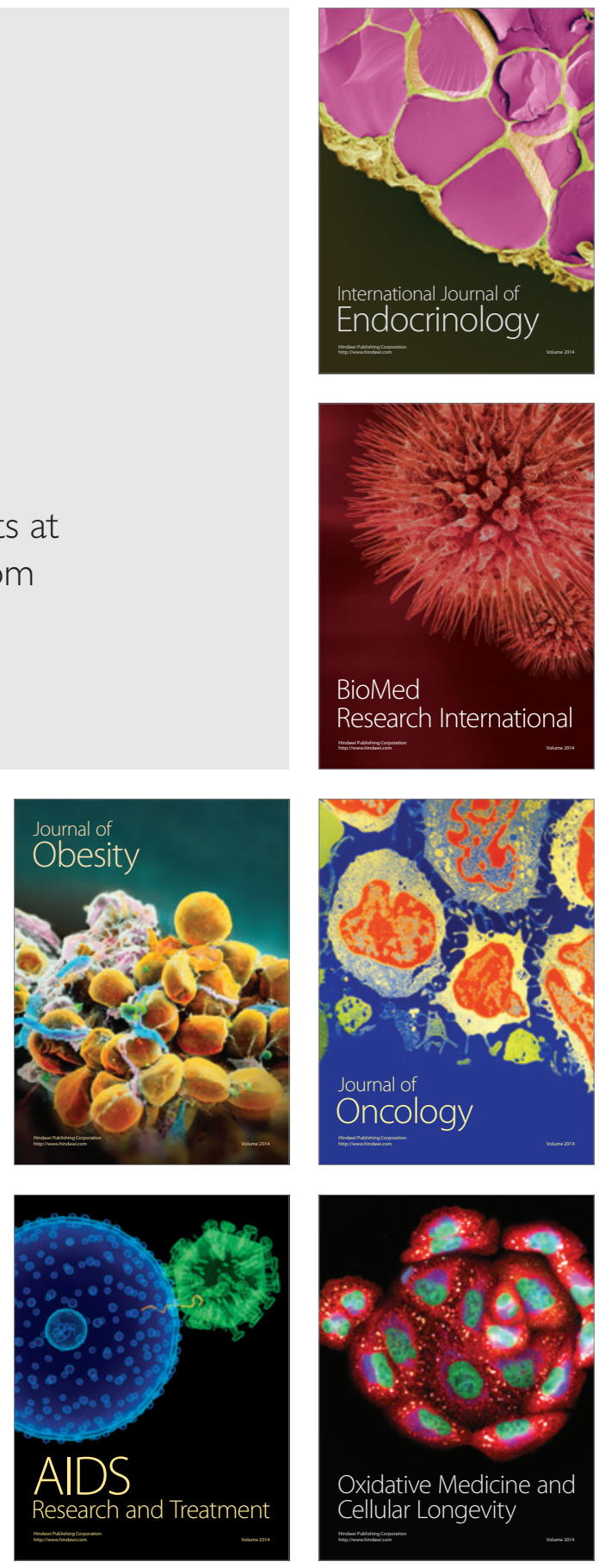